\title{
Global Health Education, a Path to Productivity and Awareness - an Indian Perspective
}

\author{
Ipseeta Menon (Corresponding author) \\ 23, Kirpal Appartments, 44, I. P. Extention, Patparganj, Delhi - 92, India \\ Tel: 91-981-119-4629Ｅ-mail: ipseeta@hotmail.com; ipseetam@gmail.com \\ Dr. Ipseeta Menon \\ I. T. S CDSR, Muradnagar, Ghaziabad \\ Dr. Hari Parkash \\ I.T.S Group of Institutions, Muradnagar, Ghaziabad
}

Received: May 4, 2011 Accepted: May 17, 2011 doi:10.5539/gjhs.v3n2p187

\begin{abstract}
Global Health Education strives to improve the health status and life expectancy of low-income and minority populations and other urban and rural areas with populations with serious unmet health needs. Global Health threats affects all of us like infectious diseases, natural and humanitarian crisis, malnutrition and contaminated foods, toxic substances, biological and chemical terrorism, rising social inequalities and highly vulnerable populations, weak inefficient or dysfunctional health systems affect the health of people all over the world. India which is progressing immensely economically in the global platform would stag behind if it gets to compromise on the country's health issues. Therefore this is a bird's eye view of the current health education programs being conducted in India.
\end{abstract}

Keywords: Global Health Education, Programs, Projects, India

\section{Introduction}

Global health is the health of populations in a global context and transcends the perspectives and concerns of individual nations. Health problems that transcend national borders or have a global political and economic impact are often emphasized as it can have serious consequences. It has been defined as the area of study, research and practice that places a priority on improving health and achieving equity in health for all people worldwide. Global health is about worldwide improvement of health, reduction of disparities, and protection against global threats that considers no national borders. With diseases like AIDS, cholera, dengue fever, H1N1 flu lurking and taking lives of so many Indians in recent times jolts us to realize the reality and educate the people to avoid such diseases and lead a healthy life. Global health education should be emphasized to every medical professional and health workers to take the task seriously so that the nation is completely void of any such diseases thus taking the country a step ahead economically and politically prominent in the global scenario.

\section{Indian scenario}

With more than one billion people, India is the second most populous country in the world accounting for 17\% of the world's population. Following independence, India has pursued a policy of planned economic development until the early 1990s, when it shifted to structural adjustment policies and liberalization. Subsequently, the Indian economy grew at a fast rate though concerns on equity and poverty persist. The country has recently become one of the world's fastest growing economies with an average growth rate of eight percent over the past three years. It has emerged as a global player in several areas, including information technology, business process outsourcing, telecommunications, and pharmaceuticals. The demographic profile of India is changing with an ageing population. The subcontinent is characterized by large diversities in geographical regions, socio-cultural groups, and health needs. 
While India is being propelled to a position of international eminence, it faces three main groups of health challenges: first, dealing effectively with unfinished agendas of communicable diseases, maternal and child health, and health systems strengthening; second, dealing with new emerging challenges such as the premature burden of non-communicable diseases (NCDs), and third, dealing with globalization related issues while contributing to the management and shaping of the global policy environment.

\subsection{Global health education programs of India}

Global Health Education programs are designed to help you grow personally and professionally. They invite you to immerse yourself in another culture, experience healthcare delivery in a new setting, and deepen your understanding of yourself and the global community. In today's world we often see the uneven distribution of healthcare that leaves many impoverished communities underserved. Economic, political, and social factors all contribute to people's access to healthcare, both internationally and at home. Increasingly, we need culturally and linguistically competent healthcare providers around the world to address these inequities. Child Family Health International's (CFHI) is one such brilliant program. Child Family Health International's (CFHI) Global Health Education Programs combine instruction, experience, service, and reflection to create a model that supports physicians, clinical sites and communities abroad, addresses the healthcare needs of the underserved, and adds an unforgettable experiential element to each program participant's professional development. Few objectives of CFHI are to develop a larger sense of cultural competency, observe and develop existing clinical skills, broaden public health knowledge, develop creativity in problem-solving, deepen your commitment to service and promote medical supply conservation to name a few.

\subsection{Catch them young - health education}

This is a program started in 2007 in India, in Pawananagar and through the help of local people they protect the youth against social and sexual risks by providing education and outreach.

\subsection{Than gaon clinic}

This program was started in 1998 in Than Gaon, India. The aim was to support an ongoing operation to maintain a successful health clinic in Than Gaon and 28 surrounding villages. This is to serve and educate the urban and rural people who stay in the foothills of Himalayas.

\subsection{CFHI - leprosy/HIV/AIDS}

This started in Mumbai in 2006-2007, and helps in providing social and healthcare support to communities living with infectious diseases. It brought about support and hope partners succeeded in bringing support and hope to many sufferers of these diseases by providing reconstructive surgeries to 30 leprosy patients, special footwear to another 50 such patients and CD4 count tests for $100 \mathrm{HIV}+$ patients.

\subsection{Sight for all}

Sight for All was a wonderful program which helped Indian and global health issues and focused on India's high demand for basic eye care. This was done in Delhi, India through the help of VENU Eye Institute and Research Center. India gives a statistics of 45 million people are visually impaired; 12 million are blind, 1 in 3 of three of the world's blind individuals is Indian and $80 \%$ of the blindness in India is either curable or avoidable.

\subsection{Health and education foundation projects of India}

Relevant education and healthcare is needed for people to widen their awareness and increase productivity. Innovative and sustainable development initiatives with community support, sustainability, are what these projects aim for:

\subsection{Teach - plus project}

Train and Educate Adolescents with Community Help (TEACH-Plus) Project, the Reading Room Program for children of primary school going age, under Government of India's Sarva Shiksha Abhiyaan - SSA started in 2003 through ABHAS (Action beyond help and support) helps adolescent girls from the urban slum community of Tughlakabad, into the formal school systems. The TEACH Project worked closely with adolescent girls, parents, education committees, educators and field level functionaries, remedial education classes, regular counseling to the girls and mothers, interaction with the school teachers, and regular tracking of academic progress were some of the interventions which promoted girl's education.

\subsection{Gate Bihar, India}

Girls Access to Education in Bihar (GATE-Bihar), India which started in 2006 includes basic literacy, extensive information on health and sanitation, as well as information on child rights, trafficking and, safe migration. 


\subsection{South India girl initiative}

This started in 2007 to ameliorate the social, environmental, and economic conditions that impede girls' education and decrease girls' vulnerability to sexual exploitation and abusive forms of child labor in Andhra Pradesh and Tamil Nadu States. This aims in improving the quality and effectiveness of their educational and social development programs for girls; developing and testing strategies to engage parents, community leaders, schools, and government officials to support, promote and advocate for girls' education.

\subsection{Combat child labor in India}

Child labor, particularly those forms that endanger children's health and general well being, is common in rural India. In rural Andhra Pradesh (AP), where families are highly dependent on agriculture for their livelihood, children, especially young girls (ages 8-15), are employed in the cotton seed industry, are often exposed to hazardous chemicals used on cotton, work long hours, and receive meager pay for their work. Many of the estimated 248,000 children employed in the cotton seed industry in AP are not attending school -- many have dropped out and almost a third has never attended.

\subsection{Oral health education- Indian scenario}

The population has risen from 850 million in 1990 to 1.18 million in 2010 with a population growth percentage remaining at 1.5 percent. India consists of twenty-eight states, and the principal unit of administration in each state is a district, which is further divided into community development blocks. There are 3708 such blocks in India, each of which caters to a population of 80,000 to 120,000 . There are about 11,900 faculty members, both in government and private sector, and around 17,660 dental graduates coming out yearly in India, so if they assist in the oral health education programs it could prove beneficial.

A study showed that the children studying in government schools had lower awareness than children in public schools, which can be attributed to the lower socio-economic background. Since India is a developing country more of such programs are recommended to bring about the desired change for the country.

As health education has spread its horizon on the Indian sky so also the oral health education. Various programs are being launched to care for the oral health of the people of India. Some of them are Colgate Bright Smiles Bright Future, Muncipal Oral Hygiene Project, Trinity Care Foundation Programs.

\subsection{Colgate bright smiles bright future}

Oral health educational program worldwide was developed to teach children oral health habits of basic hygiene, diet and physical activity. This program also encourages dental professionals, public health officials, civic leaders and, most importantly, parents and educators to come together to emphasize the importance of oral health as part of a child's overall physical and emotional development. Under this program, conducted by Colgate-Palmolive, India, children in primary schools receive instructions in dental care from members of the dental profession and Indian Dental Association. Education is imparted with the aid of audio-visuals and printed literature created by the company. The Teachers Training program is an integral part of the School Dental Health program, conducted regularly across the country to promote preventive dental health care. Colgate also launched its first-ever online school curriculum featuring fun and entertaining activities Training in the basics of oral health care is imparted to school teachers. This helps them play a significant role in preventive oral care by inculcating good oral care habits in the students. The Teachers Training Program forms a vital part of the Colgate Bright Smiles, Bright Futures Program. Till date, 243,500 teachers' have been trained under this program. Colgate-Palmolive India continues its march in the area of spreading oral health awareness through the School Dental Health Education Program. Under this Program, since 1976 over 83 million school children in rural and urban parts of the country, in the age group of 6-12 years have been reached out. Members of various IDA local branches and professional oral care organizations organized the Program across the country with the help of audio-visual aids, posters, charts and demonstration of right brushing techniques.

\subsection{Municipal oral hygiene project}

AmeriCares India - Municipal Civic School Oral Hygiene Progect: A project in collaboration with Municipal Corporation of Greater Mumbai (MCGM). AmeriCares launched operations in India in 2006 with the establishment of an office in Mumbai. This is licensed by the Indian Food and Drug Administration and maintains international standards for handling pharmaceuticals. The project objective is to reduce tobacco consumption and increase awareness among Indian adolescent and youth about the positive impact of good oral hygiene and good health. Practically, the program aims to promote healthy living and to prevent young people from ever developing a dependence on tobacco. Basic education about oral hygiene, disease prevention and the effects of tobacco usage, coupled with powerful visuals incorporating statements by well known personalities with youth appeal will focus the message on the positive impact of good health habits. The project includes the 
following components: Education on oral hygiene and disease prevention, demonstration and practice of tooth brushing techniques, procurement and introduction of hygiene products, development and introduction of multi lingual educational materials, strong visual presentation of effects of tobacco usage, star support in conveying anti tobacco message, mobile Tobacco cessation clinics for those wishing to stop using tobacco, behavioral counseling, medication, and nicotine replacement therapy for habitual users that voluntarily enter the program, training and curriculum transfer for long-term continued education, midterm and final program evaluation, documenting and highlighting best practices, addressing potential opportunities for scale up or piloting in other schools, feedback and reinforcement of message at regular intervals.

\subsection{Trinity care foundation}

Trinity Care Foundation is a Non-Profit Organization based in Bangalore, India dedicated to School Health Programs, Facial Deformity Programs and Oral Cancer Programs working with community organizations, educational Institutions and involving Government, Industry and the Medical Profession. They conduct public health camps, dental screening and treatment camps, school health programs, medical camps and blood donation camps.

\section{Conclusion}

With increase of many such educational programs there is a possibility of improving the health and dental health statistics of India. When possible, the inclusion of the health and dental public health programs in schools is recommended so that public health and dental public health students can learn about each other's disciplines and share a common educational experience. Dental education programs are effective in improving the knowledge levels of most children. Reinforcement of knowledge is absolute necessary and teachers training program can ensure continuity of the reinforcement. Certain interventions like multi-component interventions comprising information materials, educational-institution interventions and, in rural contexts, community peer interventions are acceptable and feasible and likely to be effective for health promotions.

\section{References}

Brown, T. M., Cueto, M., \& Fee, E. (2006 Jan). The World Health Organization and the Transition from "International" to "Global". Public Health. AJPH, 96 (1). http://dx.doi.org/10.2105/AJPH.2004.050831

Goel, P., Sehgal, M., \& Mittal, R. (2005). Evaluating the effectiveness of school based dental health education programs among children of different socio-economic groups. J Ind Soc Prevov Prev Dent, 131-135.

Koplan, J. P., Bond, T. C., Merson, M. H., et al. (2009). Consortium of Universities for Global Health Executive Board. Towards a common definition of global health. Lancet, 373, 1993-1995. http://dx.doi.org/10.1016/S0140-6736(09)60332-9

[Online] Available: http://abhasindia.org/Teachplus.php

[Online] Available: http://www.ajph.org/cgi/reprint/96/1/62

[Online] Available: www.americares,org

[Online] Available: www.cfhi.org

[Online] Available: www.cfhi.org/web/index.php/program/304

[Online] Available: www.cfhi.org/web/index.php/program/49

[Online] Available: www.cfhi.org/web/index.php/program/50

[Online] Available: www.cfhi.org/web/index.php/program/54

[Online] Available: www.colgate.co.in

[Online] Available: www.ilo.org

[Online] Available: www.mapsofindia.com.

[Online] Available: www.searo.who.int/en/1174

[Online] Available: www.trinityfoundationcare.org

[Online] Available: www.worlded.org

Prakash, H., Duggal, R., \& Mathur, P. V. (2006). Guidelines for meaningful and effective utilization of man power in Dental Colleges for Primary prevention of Oro dental problems in the country, GOI - WHO collaborative program.

Tandon, S. (2004). Challenges to the Oral Health Workforce in India. J Dent Educ, 68 (7 suppl), 28-33. 